\title{
Minimal intervention dentistry II: part 4. Minimal intervention techniques of preparation and adhesive restorations. The contribution of the sono-abrasive techniques
}

IN BRIEF

- Outlines the sono-abrasion technique for selective preparation of enamel and dentine.

- Describes the therapeutic principles and choice of instrumentation.

- Illustrates appropriate clinical situations for sono-abrasion in the preservation and optimisation of tissue bonding for both initial lesions and advanced lesions.

\author{
F. Decup ${ }^{1,2}$ and J-J Lasfargues ${ }^{* 1,3}$
}

The concept of minimal intervention in oral medicine is based on advances in biological sciences applied to the dental organ. Many cultural barriers, economic as well as technical, have thwarted the application of micro-invasive conservative techniques by the general practitioner. Emerging technologies do not remove all obstacles but promote the integration of less invasive techniques in daily practice. Sono-abrasion is a technique for the selective preparation of enamel and dentine offering excellent efficacy, quality and safety. The authors describe the therapeutic principles, the choice of instrumentation and its mode of action and discuss its interest in adhesive restorative dentistry. The illustrated clinical situations focus on the preservation and optimisation of tissue bonding for both initial lesions and advanced lesions.

\section{MINIMAL INTERVENTION DENTISTRY II \\ 1. Contribution of the operating microscope to dentistry \\ 2. Management of caries and periodontal risks in general dental practice \\ 3. Management of non-cavitated (initial) occlusal caries lesions - non-invasive approaches through remineralisation and therapeutic sealants \\ 4. Minimal intervention techniques of preparation and adhesive restorations. The contribution of the sono-abrasive techniques \\ 5. Ultra-conservative approach to the treatment of erosive and abrasive lesions \\ 6. Microscope and microsurgical techniques in periodontics \\ 7. Minimal intervention in cariology: the role of glass-ionomer cements in the preservation of tooth structures against caries \\ 8. Biotherapies for the dental pulp \\ This paper is adapted from: Decup F, Lasfargues $\mathrm{J} \mathrm{J}$. Préparations et restaurations adhésives a minima. Apport des techniques sono-abrasives. Réalités Cliniques 2012; 23: 201-212.}

${ }^{1}$ Faculté de Chirurgie Dentaire, Université Paris Descartes, 1 rue Maurice Arnoux, 92120 Montrouge Service d'Odontologie, Hôpital Charles Foix, APHP, 94200 Ivry sur Seine, France; ${ }^{3}$ Service d'Odontologie Hôpital Bretonneau, APHP, 23 rue Joseph de Maistre, 75018 Paris, France.

${ }^{*}$ Correspondence to: Professor Jean-Jacques Lasfargues Email: jean-jacques.lasfargues@brt.aphp.fr;

Tel: +33153111430

\section{Refereed Paper}

Accepted 15 November 2013

DOI: $10.1038 /$ sj.bdj.2014.246

${ }^{\circ}$ British Dental Journal 2014; 216: 393-400

\section{INTRODUCTION}

For the past 20 years traditional operative dentistry has evolved towards a more conservative concept, the main objective of which is the increased preservation of dental tissue. . $^{1,2,3}$

New operative techniques for caries excavation and cavity preparation have developed, offering less patient discomfort and less tissue removal. ${ }^{4,5}$ These techniques can be classified as mechanical and nonmechanical. The first involves manual and rotary excavation, sono-abrasion and ultrasonic abrasion. The second involves chemo-mechanical and enzymatic air abrasive methods and lasers.

The generic term of sono-abrasion covers the oscillatory diamond abrasive techniques that have been developed in the 1990s specifically for the preparation of small proximal cavities..$^{6-8}$ In the last decade, sonoabrasion has benefited from technological developments, the instrumentation is diverse and indications for it use have expanded.

The purpose of the present article is to review the contribution of sono-abrasive operative methods to the preparation of dental hard tissues and to discuss their benefits in operative dentistry.

\section{SONO-ABRASIVE INSTRUMENTATION}

A sound is a wave produced by the mechanical vibration of a carrier fluid or solid, and propagated through the elasticity of the surrounding medium.

Depending on the frequency of the wave, the sounds are classified into different categories: those that we use in dentistry are sound and ultrasound.

- Infrasound $=1-20 \mathrm{~Hz}$

- Sound $=20-20,000 \mathrm{~Hz}$

- Ultrasound = 20-1,000 KHz

- Megasound $=1-100 \mathrm{MHz}$

- Hypersound = >100 MHz

\section{Oscillating systems}

Sonic handpieces in current use create sound with a frequency about $8,000 \mathrm{~Hz}$ to $15,000 \mathrm{~Hz}$, with three power levels depending on the treatment being undertaken and deliver an oscillating amplitude $<200 \mu \mathrm{m}$. The vibrations are generated by the compressed air from the dental unit, which is transmitted by a tube to the handpiece. No additional generator is required. The pressurised air drives a rotor, which causes a circular oscillation to be transmitted to the tip. The tip moves with a tri-dimensional elliptical motion.

Handpieces of the most recent generation were chosen, producing limited noise $(<70 \mathrm{~dB})$ with spray cooling, integrated LED light and a multiflex connection (eg: SONICflex Lux 2003L ${ }^{\circledR}$, KAV0; SF1LM ${ }^{\circledR}$, Komet; ZA-55LM $\left.{ }^{\circledR}, \mathrm{WH}\right)$.

Ultrasonic handpieces operate at high frequency, about $20,000 \mathrm{~Hz}$ to $40,000 \mathrm{~Hz}$ (by comparison, the frequencies used by 


\begin{tabular}{|c|c|c|c|c|c|}
\hline & \multicolumn{2}{|l|}{ Sono-abrasion } & \multicolumn{3}{|l|}{ Ultrasono-abrasion } \\
\hline & KAVO Sonicsys/Sonicflex ${ }^{\circledR}$ & KOMET SonicLine ${ }^{\circledR}$ & ACTEON SATELEC ${ }^{\circledR}$ & EMS $^{\circledR}$ & $\mathrm{WH}^{\circledR}$ \\
\hline $\begin{array}{l}\text { Occlusal pits and } \\
\text { fissures, occlusal } \\
\text { micro-preparations }\end{array}$ & $\begin{array}{l}\text { SF } 45014 \\
\text { SF849.000.009 (conical) } \\
7139 / 04 \text { (small round) } \\
42311 \text { and } 43218 \text { (small } \\
\text { round with shaft) }\end{array}$ & $\begin{array}{l}\text { SF49. } 009 \text { NP1/2 } \\
\text { SF69.000 (small ovoid) }\end{array}$ & EX1 (ball ø 1.7) & $\begin{array}{l}\text { PF6062A (conical) } \\
\text { SB DS-057A (round) }\end{array}$ & Special tip1R \\
\hline $\begin{array}{l}\text { Micro-preparations for } \\
\text { approximal cavities }\end{array}$ & $\begin{array}{l}\text { Sonicsys micro }{ }^{\circledR} \text { : } \\
\text { hemispherical small and large, } \\
\text { bevel shape }(30-31 ; 32-33 \text {, } \\
58-59) \\
\text { angle (tunnel) (53-54) }\end{array}$ & & $\begin{array}{l}\text { Kit Excavus }{ }^{\circledR} \text { ref. Fo0739: } \\
\text { EX2 (Mesial, } 1 / 2 \text { boule } \varnothing 1.7 \text { ) } \\
\text { EX3 (Distal, } 1 / 2 \text { boule } \varnothing 1.7 \text { ) } \\
\text { EXR (right- } 45^{\circ}, 1 / 2 \text { ball } \emptyset 1.7 \text { ) } \\
\text { EXL (left- } 45^{\circ}, 1 / 2 \text { ball } \varnothing 1.7 \text { ) }\end{array}$ & $\begin{array}{l}\text { SBm/d DS-061A/062 } \\
\text { A: } 1 / 2 \text { round tip }\end{array}$ & $\begin{array}{l}\text { Special tip 3RM } \\
\text { and 3RD }\end{array}$ \\
\hline Dentine excavation & $\begin{array}{l}71 \text { 23/07 (multiblade round) } \\
71 \text { 39/04 (round diamond) }\end{array}$ & & & & \\
\hline $\begin{array}{l}\text { Approximal boxes } \\
\text { Inlays, onlays }\end{array}$ & $\begin{array}{l}\text { Sonicflex prep gold (49-50) } \\
\text { Sonicflex prep ceram (51-52) } \\
\text { Sonicflex prep CAD/CAM }\end{array}$ & & & $\begin{array}{l}\text { SM and SD tip (approximal } \\
\text { box, direct restoration }\end{array}$ & \\
\hline Veneers & & SF 8,850 016 & & VE DS-064A (hemi-ogive) & Special tip 2R \\
\hline $\begin{array}{l}\text { Preparations of } \\
\text { crown core } \\
\text { (partial and } \\
\text { peripheral prep) }\end{array}$ & $\begin{array}{l}\text { SF862 }(0.14) \text { : flame } \\
\text { SF979 }(0.14,016) \text { and SF } 8,979 \\
(0.14,016) \\
\text { SF847KR(0.16): shoulder } \\
\text { SF 8878 KD/KM (0.18): } \\
\text { approximal preparation }\end{array}$ & $\begin{array}{l}\text { SF979 }(0.14,016) \\
\text { SF 8,979 }(0.14,016) \\
\text { SF862 }(0.14): \text { flame } \\
\text { SF847KR(0.16): shoulder } \\
\text { SF 8878 KD/KM (0.18): } \\
\text { approximal preparation }\end{array}$ & 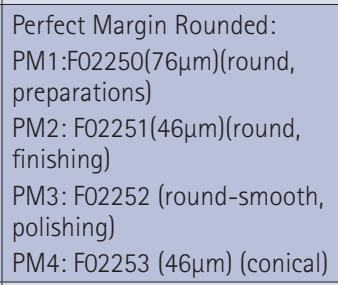 & $\begin{array}{l}\text { VE DS-064A (approximal } \\
\text { preparation) }\end{array}$ & Special tip $2 R$ \\
\hline $\begin{array}{l}\text { Interproximal finishing } \\
\text { (stripping and shaping) }\end{array}$ & & $\begin{array}{l}\text { Lance shaped blade, single- } \\
\text { sided coating } \\
\text { Stripping (flat surface } \\
\text { active): } \\
\text { SFD1F and SDM } 1 F\left(60^{\circ}\right) \\
\text { SFD3F and SDM3F }\left(15^{\circ}\right) \\
\text { Shaping (convex surface } \\
\text { active): } \\
\text { SFD2F and SDM2F }\left(60^{\circ}\right) \\
\text { SFD4F and SDM4F }\left(15^{\circ}\right)\end{array}$ & & & \\
\hline
\end{tabular}

ultrasonic cleaning devices are 100,000 Hz). They also benefit from LED technology and are used on piezoelectric generators with adjustable irrigation spray and with enough power, depending on the choice of treatment, for scaling, endodontics and micro-dentistry restorative techniques (eg Piezon Master $700^{\circledR}$, EMS; PMax Newtron Satelec ${ }^{\circledR}$, Acteon).

The operating principle is based on an alternating current amplified by a generator, led through ceramic pellets. The latter, contained in the handpiece, react by changing shape (elongation and contraction). As a result, the alternation amplifies the vibration, which is transmitted to the tip and provides a hard working capacity. It is an application of the inverse piezoelectric effect, described by Pierre and Marie Curie in 1880.

\section{Different working tips}

Diamond technology has been improved and offers more effective and sustainable diamond-coated instruments that limit pollution of the oral environment. ${ }^{9}$ The diamond coating is achieved by electroplating. Currently, a manufacturing process for chemically depositing a diamond film by vapour deposition (CVD) is being developed to improve bonding between the diamond and the metal, and to prolong the life of the instruments. ${ }^{10}$ Normally, natural diamond grit is perfectly calibrated by size and wear occurs by micro-splitting, the fracture of the diamond particle, creating new edges, which allows continuous abrasion. A specific binder is necessary to avoid loss of the diamond grit. For clearing the space between crystals and to avoid overheating the diamond surface can be cleaned using a special cleaning stone or using an ultrasonic bath. In use the tip must be well fixed because of vibration: torque wrenches are available for efficient tightening and to avoid loosening and loss of the tip in the mouth.

The generic form of the tip (very long axis and miniaturised working end) allows maximum visual inspection and simplified access, including to areas inaccessible to a bur. These characteristics make it the instrument of choice for working with optical magnifiers. A range of tips designed for restorative dentistry is available, with many partially or completely designed for diamond coating for use with suitable pneumatic or ultrasonic piezoelectric hand pieces (Table 1).

The choice of tip depends on the purpose; it can be a cavity preparation entirely done by sono-abrasion (or localised removal of extension of the lesion), to prepare and finish the margins of a preparation, or to smooth and finish interproximal surfaces of composite resin restorations.

The working action of sono-abrasive tips is based on four different effects:

- The vibration, characterised by frequency (determines amplitude and the path of the tip) controls the impact of the instrument on the tissue. It varies depending on the power provided by the generator, on the 

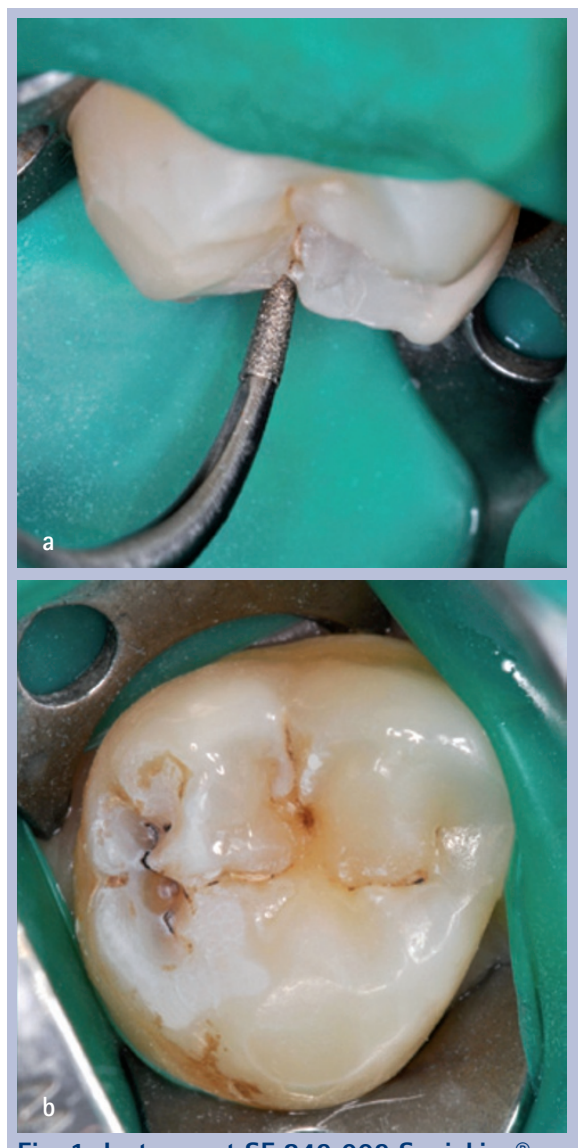

Fig. 1 Instrument SF 849009 SonicLine ${ }^{\circledR}$ (Komet) for pits and fissures, which allows opening and preparation of the carious distal occlusal fissure of tooth 27. a) Tip in place; b) Clinical result

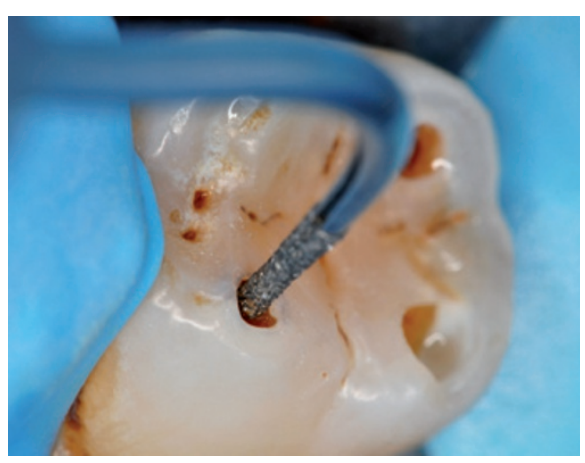

Fig. 2 Instrument 42311 Sonicflex ${ }^{\circledR}$ (Kavo) (diamond-coated ball and shaft) used here for an occlusal micro-preparation where there are cavities in the cuspal tips (21-year-old patient; severe erosion since childhood)

tip in use and on the amount of fluid used with the tip (when more fluid is used, vibration is weakened)

- The abrasion is the mechanical effect associated with vibration. It depends on the grain size of the tip coating and the hardness of the tissue: the harder the tissue, the more effective the abrasion (enamel $>$ demineralised enamel $>$ dentine $>$ cement $>$ decayed tissue $>$ soft tissue). Sono-abrasion is less effective on soft substances, so it is less suitable for removing soft carious dentine but has few negative iatrogenic effects on the periodontium and soft tissues

- The thermal effect is a function of the vibration and the duration of use. It is therefore recommended to use irrigation (at least occasionally) and work by intermittent contact to avoid heating the tissue

- Cavitation is the collapse of microbubbles, formed by the ultrasonic waves in the irrigation liquid. It plays an important role in surface cleaning and debris removal.

\section{THERAPEUTIC PRINCIPLES}

\section{Sono-abrasion for enamel}

Sono-abrasion has limited efficacy on healthy enamel and increases working time compared with drilling. ${ }^{11}$ On the other hand, it can be used for the selective removal of altered enamel (demineralisation due to caries, enamel dysplasia, amelogenesis imperfecta, molar-incisor hypomineralisation $[\mathrm{MIH}]$ etc), the removal of which occurs preferentially before the removal of correctly mineralised zones.

The surface quality obtained with sonoabrasion makes the sono-abrasion system an excellent one for finishing margins. Lack of enamel cracks and a good seal for bonding has been highlighted (see discussion). The 'single-sided design' (diamond coated on one side) helps protect the adjacent teeth. ${ }^{12}$

\section{Sono-abrasion for dentine}

The effectiveness of sonic abrasive diamond tips on carious and softened dentine is less than that of rotary instruments (ceramic or tungsten burs). The removal of affected, secondary or sclerotic dentine (the hardness of which is near to that of normal dentine) is more acceptable. In particular, sonic abrasion is suitable for treating cervical lesions that generally have relatively hard secondary tissue surfaces.

Sonic abrasion does not prevent the formation of smear layer, howewer, some studies have reported open tubules with no smear after treatment with ultrasonic tips. ${ }^{13}$ There may be micro-cracks in the surface, but this remains to be demonstrated. ${ }^{14}$ The action of diamond tips can achieve the removal of damaged tissues, leaving a surface suitable for standard adhesive procedures. ${ }^{15}$

\section{OPERATIVE METHODS}

\section{Treatment of initial lesions (stages one and two)}

The technology of ultrasonic abrasion is particularly interesting for initial lesions. Because of their small size and their relatively superficial location, preparation is limited to a localised opening in enamel and subsequent removal of the underlying infected area confined to the outer third of dentine. In the most favourable cases, these two operations can be done concurrently by selecting a single sonic abrasion tip of suitable size and dimension. In general, it is not necessary to complete the excavation by drilling. If necessary, the abrasive work of the tip is helped by point access in the enamel, made with a small diamond bur.

\section{Occlusal mini-cavities}

The sono-abrasive preparation involves the occlusal pits and fissures. It will either insert a pointed working tip in the case of a convoluted preparation strictly limited to the fissures, or a ball or 'champagne cork' shaped tip of small diameter, if the lesion is located in a pit and extends in depth beyond the dentinoenamel junction (DEJ). There are round multi-blade carbide tips for excavating carious dentine, but they are of limited interest; either the sonoabrasive tip is adequate or else it is preferable to excavate completely by drilling, possibly with a size 08-012 ceramic bur (eg: K1SM 204 CeraBur $^{\circledR}$, Komet), which offers a lower risk of over-extension compared with conventional rotary instruments. ${ }^{16}$

Sono-abrasion is particularly interesting from the point of view of tissue economy. It allows marginal fossae to be explored without weakening of the marginal ridges. Opening distal occlusal fissures in maxillary molars, where the risk of over-preparation is increased by difficulty of access and poor insight, is also a good indication (Figs 1a and b). A special situation occurs in lesions in cuspal tips with caries or carious and erosion jointly. Here again, sonic abrasive tips allow simultaneous removal of damaged tissue and enamel preparation while preventing microcrack formation and limiting weakening of the zone by subjecting it to high mechanical stress (Fig. 2).

\section{Approximal mini-cavities}

The preparation of small approximal cavities for adhesive restoration by sonic abrasion has been frequently described in the work of Hugo and Stassinakis. ${ }^{17}$ The main advantage of this technique is the prevention of iatrogenic damage to the adjacent tooth, provided a diamond tip with a smooth non-working surface is used. This allows the positioning of a matrix and corner protection, if required (eg: FenderWedge ${ }^{\circledR}$ and FenderPrep Directa $\mathrm{AB}^{\circledR}$, Garrison).

The standard procedure is to open the enamel with a round diamond, then select the type of tip and either mesial or distal orientation of the working surface to complete 


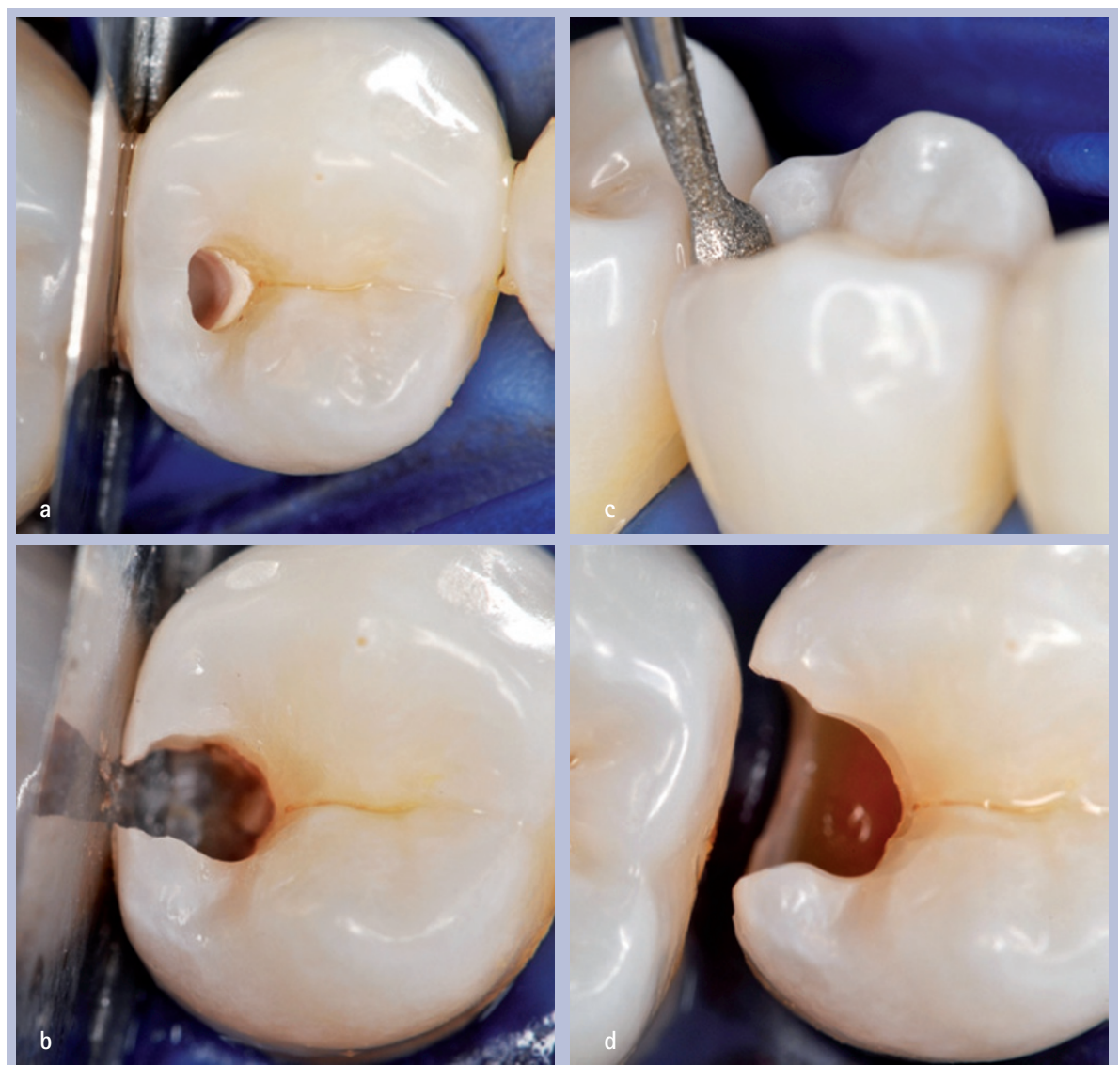

Fig. 3 Use of a hemispherical tip 33 SonicSys micro ${ }^{\circledR}$ (Kavo) for approximal cavity micropreparation. a) Access through the enamel for a diamond bur through the marginal ridge; FenderPrep, Codimed ${ }^{\circledR}$ protective system in place; b) Evaluation of the lesion after limited removal of the marginal ridge; c) Removal of carious tissue and approximal shaping with the smooth surface of tip 33 pressing against the adjacent tooth and the convex coated surface working on the outer side of the marginal ridge; d) Clinical result: note the removal of undermined enamel and the concave preparation of the approximal margin

the preparation. The tip simultaneously creates the 'mini-cavity' and finishes the cervical and proximal edges (Figs 3a-d).

Several types of preparation are possible, either with partial removal of the marginal ridge or conserving the marginal ridge: $:^{18,19}$

- A 'slot' or axial approximal mini-cavity preparation. This shape is the standard for interproximal adhesive preparations for carious lesions in accordance with the principles of minimum intervention fentistry in SiSta 2.1 and 2.2 lesions

- Mini-cavity preparations with buccolingual access, horizontal access and those with approximal tunnel access are operator-dependent. ${ }^{20}$ They are reserved for special cases, either because the lesion is distant from the interproximal contact, or because the lesion is accessible without removing the marginal ridge due to the absence of the adjacent tooth, or the embrasure has a triangular shape (the Huche index has a high value), or an ectopic tooth.

Whatever the type of access, the practitioner must operate under rubber dam to confine the interdental papilla and must use magnification to guide the tip in the areas where caries may have extended and to manage the removal of hard tissue (Figs 4a and b).

\section{Cervical mini-cavities}

Direct access in the cervical third of the buccal and lingual surfaces for a hemispherical instrument allows the selective removal of enamel or dentine that cannot be retained, while preserving the periodontal tissues (Figs 5a and b). If necessary, for aesthetic reasons, the same tip is useful to chamfer the cavo-surface margin of undermined enamel. This allows sclerotic blackened dentine to be 'peeled' back (although opaque flowable area if the lesion extends interproximally (Figs 6a-d).

\section{Treatment of altered} enamel smooth surfaces

Sono-abrasion is a technique for selectively structure while preserving adjacent healthy resin composites can hide discoloured areas). The tip can be used in the embrasure eliminating unsightly defects of enamel
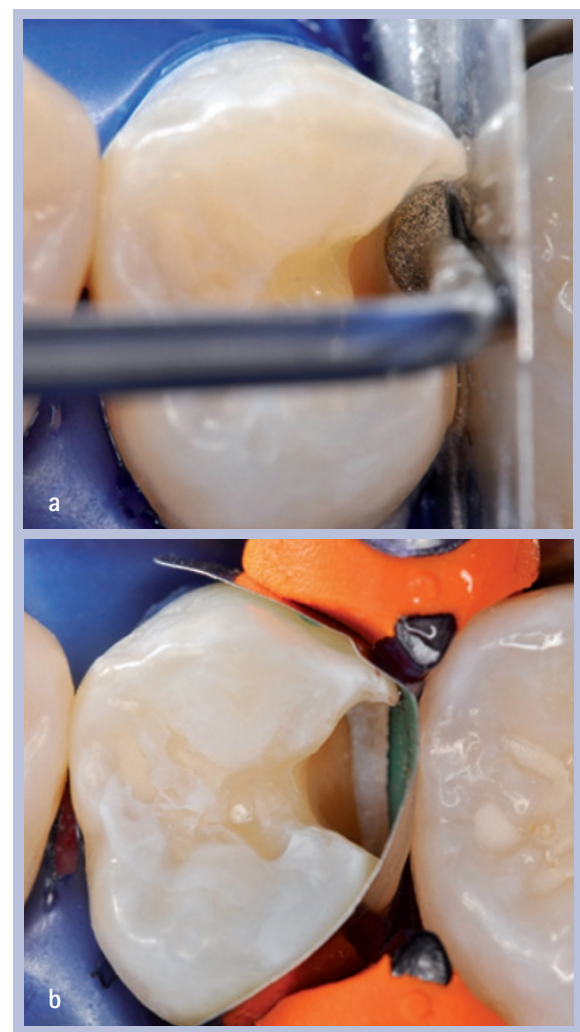

Fig.4 SonicSys micro ${ }^{\circledR}($ Kavo) hemispherical tip 33 micro for adhesive cavity preparations. a) Finishing the cervical margin, the smooth side towards the FenderPrep, Codimed ${ }^{\circledR}$ protective system; b) Clinical result: note the regularity of cervical enamel margin. A matrix system is installed (Composi-Tight 3D ${ }^{\circledR}$, Garrison) and the cavity is ready for filling

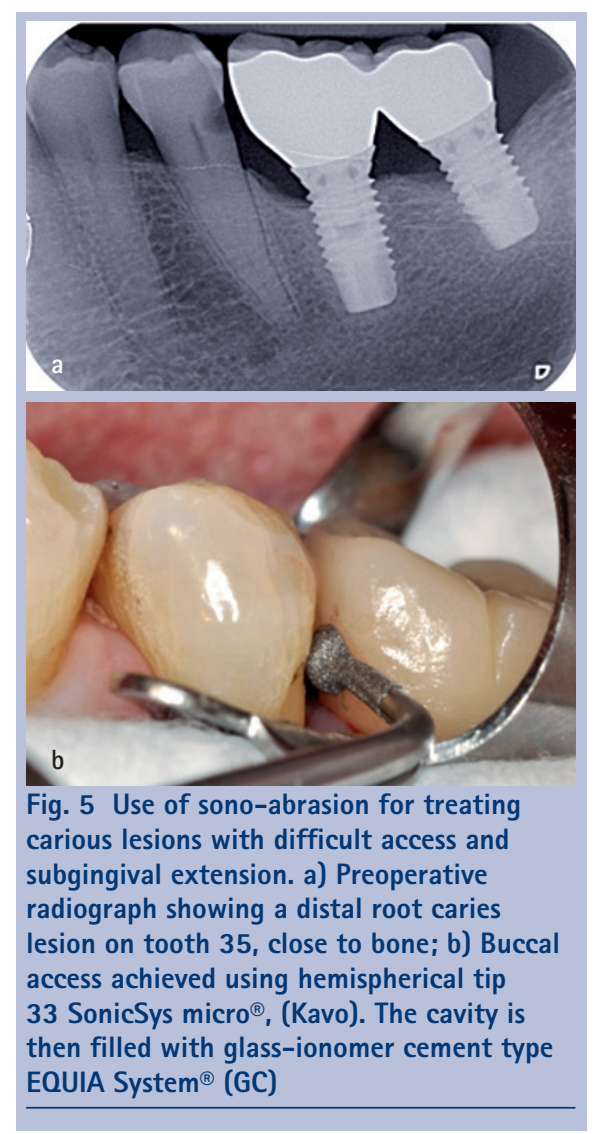



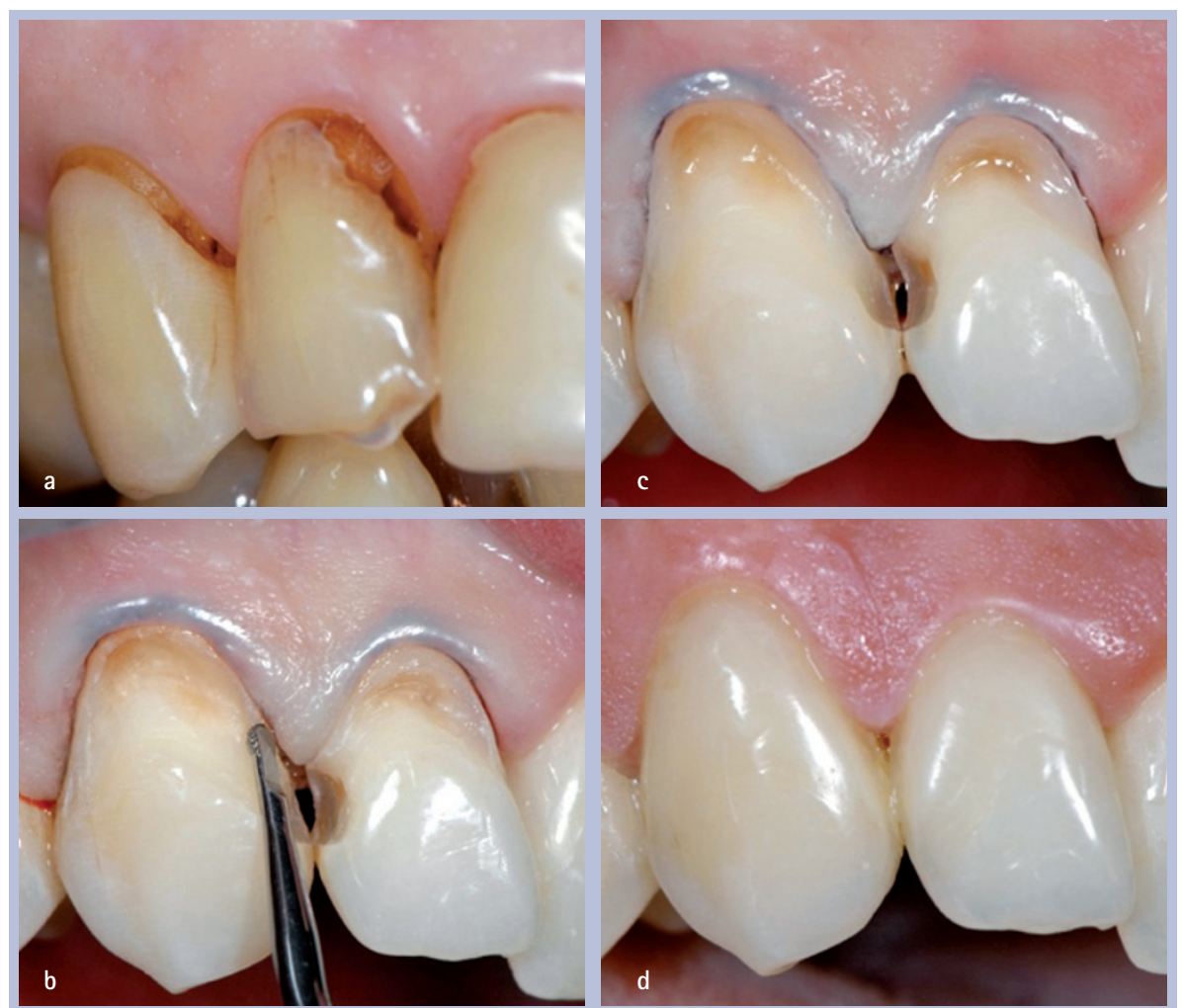

Fig. 6 Sono-abrasive preparations for the treatment of cervical lesions. a) Preoperative condition showing gingival secondary caries at site three; b) Half-round diamond tip SBd DS-061A/062 EMS ${ }^{\circledR}$ ensures excellent preservation of tooth substance and periodontal tissue; c) Inspection of preparations before bonding; d) Clinical outcome: note the good aesthetic and periodontal integration of the new composite restorations

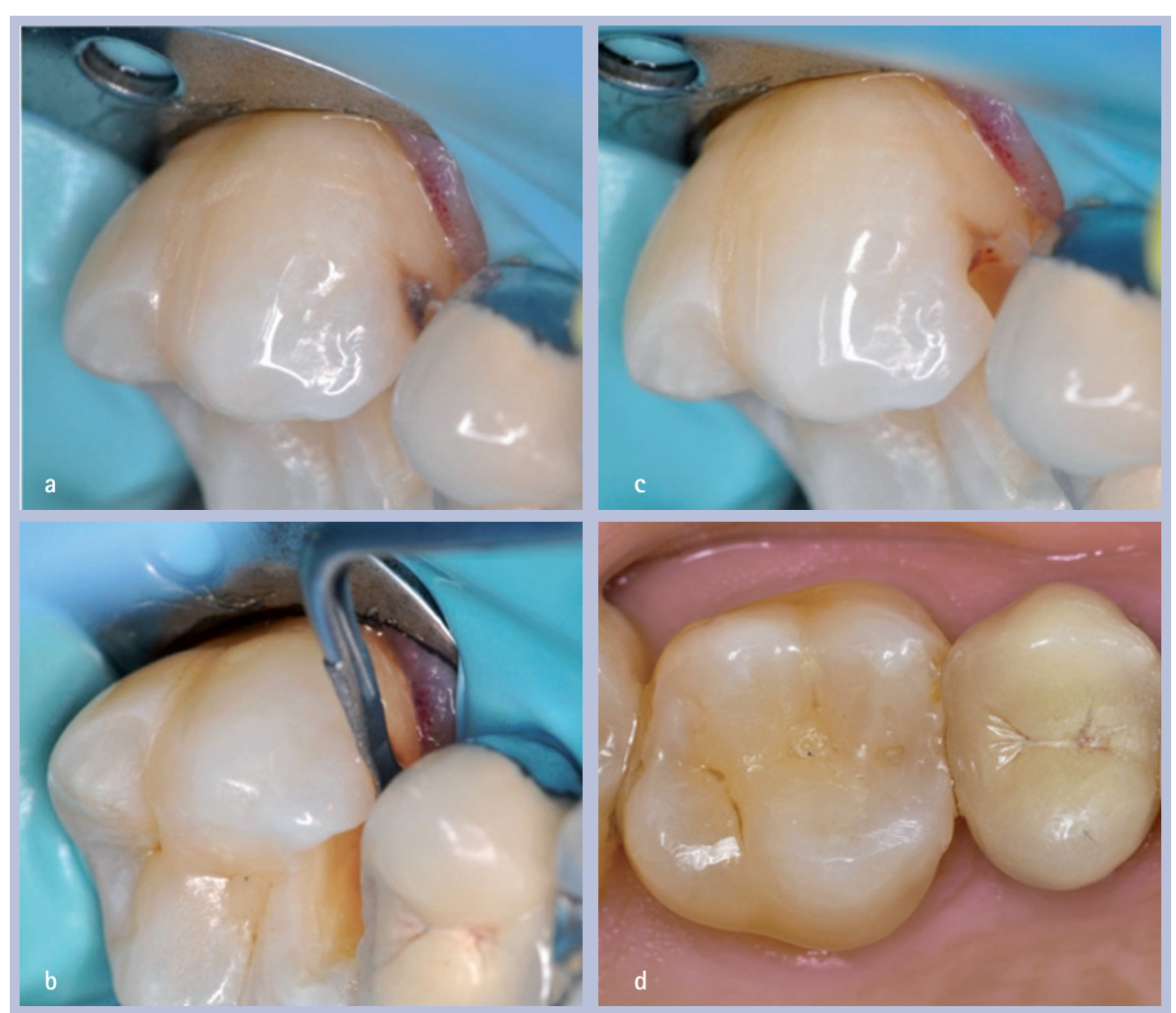

Fig. 7 Approximal secondary caries, palatal on tooth 16, associated with a fractured composite restoration requiring replacement. a) Clinical view; b) The defect is locally eliminated using a sono-abrasive tip; c) A peripheral zone of sound enamel is precisely established at the same level while maintaining the undercut; d) Clinical outcome tissue. It is particularly suitable when chemical alternatives (whitening, erosioninfiltration) are inadequate, such as in cases of dysplasia, fluorosis, $\mathrm{MIH}$ and also to hide the visible signs caries remineralisation (brown spot lesions). These surface micropreparations then require to be protected by directly or indirectly bonded partial veneers, which provide a good aesthetic integration for a minimal loss of tissue.

\section{Treatment of advanced lesions (stages three and four)}

The concept of minimal intervention dentistry can now be applied to any act of restorative dentistry. It applies, of course, to first-line interventions as described above for small lesions, but also to any treatment, which is based on preservation of tissue and facilitates hard tissue and pulp selfrepair. Thus, by limiting the extension of a preparation, by avoiding pulp damage and by repairing restorations, the practitioner is practising minimum intervention dentistry and is contributing to the longevity of functional tooth units and restorations.

Sono-abrasive diamond technology is thus not limited to the preparation of 'micro-cavities'. It is a valuable complement to operative treatment of tissue defects associated with extensive primary and secondary lesions and to improving the quality of occlusal, approximal and especially cervical margins, before direct or indirect placement of restorations.

\section{Spot elimination of tissue defects}

After initial cavity preparation, done rapidly by drilling with or without removal of an old restoration, close inspection may reveal the presence of lesion extensions in peripheral cavity areas. It is possible to access small defects (secondary caries or altered enamel), without changing the general outline of the preparation or the outline determined by the old restoration. This prevents reducing the residual wall thickness and finally to restore the occlusal form. This widens the indications for direct composite resin adhesive restorations, as these defects, isolated by the restoration, will be filled by the injected composite resin or the insertion of increments during stratification (Figs 7a-d).

\section{Preparation and finishing of cervical margins}

Although the cervical margins of a deep interproximal preparation can be established by drilling, there is a significant risk of fragmentation and loss of the residual enamel and damage to adjacent tooth surfaces. In this situation, a better cervical 


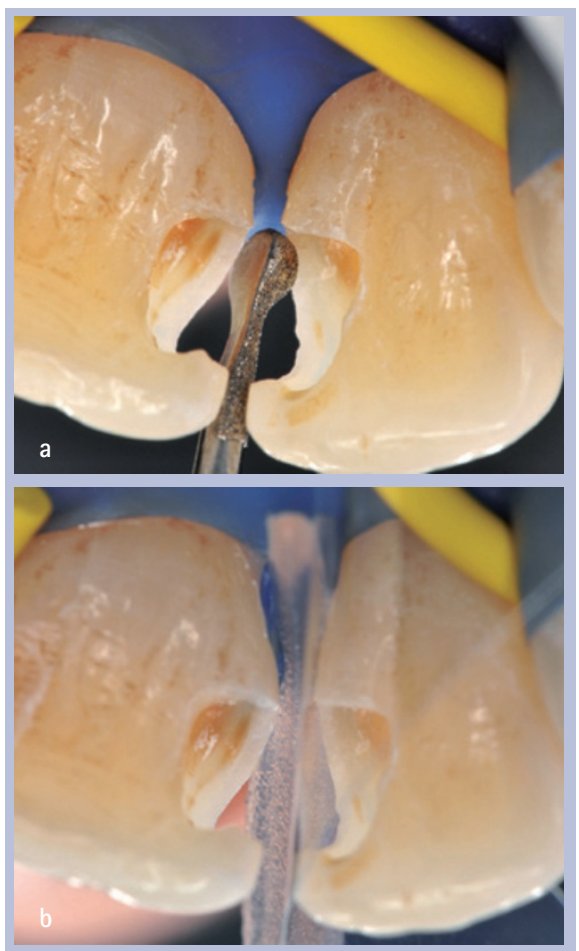

Fig. 8 Producing bevel-edge preparations for anterior approximal composites. a) Hemispherical micro tip SonicSys $32^{\circledR}$ (Kavo); b) Clinical outcome: observe the regularity of the margins produced by abrasion, conducive to quality bonding

margin (shape, resistance and surface) can be achieved safely and without concomitant damage to the adjacent tooth. An abrasive hemi-spherically shaped diamond tip is a suitable tool, for a bevelled preparation for direct restoration (Figs 8a and b), or a tip for a proximal box for inlay-onlay composite (Fig. 9). Using the handpiece on low power allows fine and non-traumatic control during the progressive removal of the enamel. This allows the adhesive material to be applied on a perfectly regular cervical step, with reduced risk of deficiencies or excesses.

To finish the transition zones at the cavity margins in the proximal box, it may be appropriate to use different tips from the Sonicline ${ }^{\circledR}$ (Komet). These tips include blade- or lance-shaped tips with single-sided diamond coating, to eliminate sharp corners and flanges while protecting adjacent teeth.

\section{Aesthetical restorative dentistry}

Another indication for sono-abrasion is the preparation and finishing of the visible margins of cosmetic ceramic or indirect composite restorations (Figs 10a and b).

First, the tooth is prepared using rotary instruments adapted to the desired finished shape (butt joint, finish line, chamfer, shoulder with rounded internal angle...). Then, specifically shaped tips can be used to establish the margins of bonded veneers, for partially adhesive restorations (or even
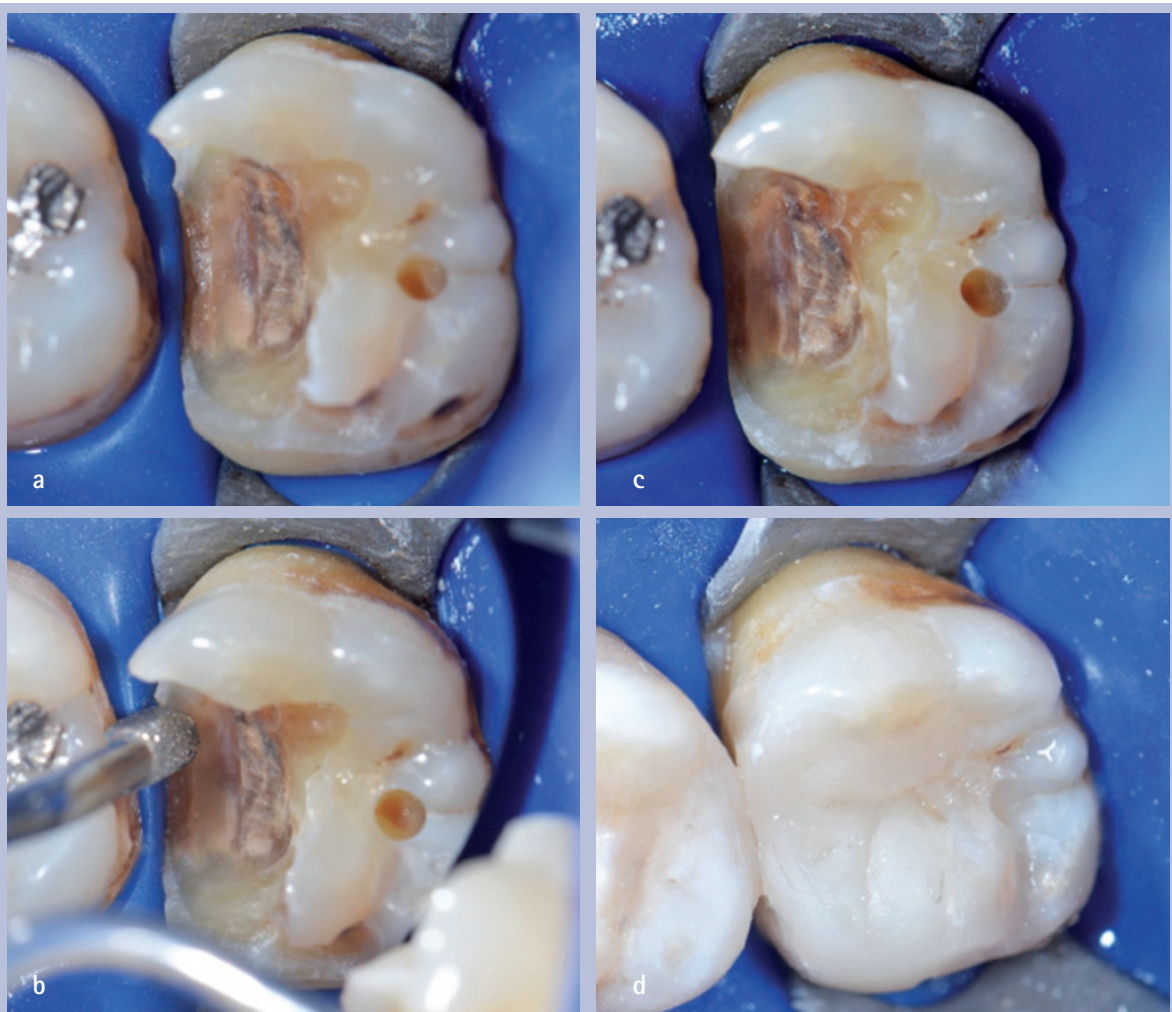

Fig. 9 Contribution of sono-abrasion to shaping the approximal boxes in posterior teeth. a) Status of the preparation after removal of the old restoration; b) Completion of a sharp edge (shoulder) with the EMS SM ${ }^{\circledR}$ tip for approximal boxes; c) Note the sharp margins produced by abrasion; d) The onlay in place

for crowns). There are tips that are fully diamond-coated with working end or with smooth no working end, others instruments are 'single-sided' for interproximal preparations. Reduction by abrasion is advantageous compared with drilling, as it reduces the risk of scratches or roughness related to jerking of burs, or damage to gums if there is accidental contact. For this reason the abrasive tip should run at low power with sufficient coolant spray before being placed on the tooth. Depending on the case, we select the diamond particle size for each instrument: medium particle size for leaving a rough surface for bonding or a fine particle size, leaving a very well defined surface for a good and accurate impression of the preparation. This precision must be maintained throughout the prosthetic chain, whether conventional or computer-aided manufacturing (CAM), to ensure a minimal tooth-prosthesis gap and to guarantee longevity of the prosthetic joint.

\section{Recontouring restorations}

Despite the development of new matrix systems with spacing specifically adapted to composite restorations (sectional matrices V3Ring ${ }^{\circledR}$, Wam or Composi-Tight $3 \mathrm{D}^{\circledR}$, Garrison), it is rare to get an ideal approximal shape immediately with perfect junction transitions without excess material along the buccal and lingual margins of the
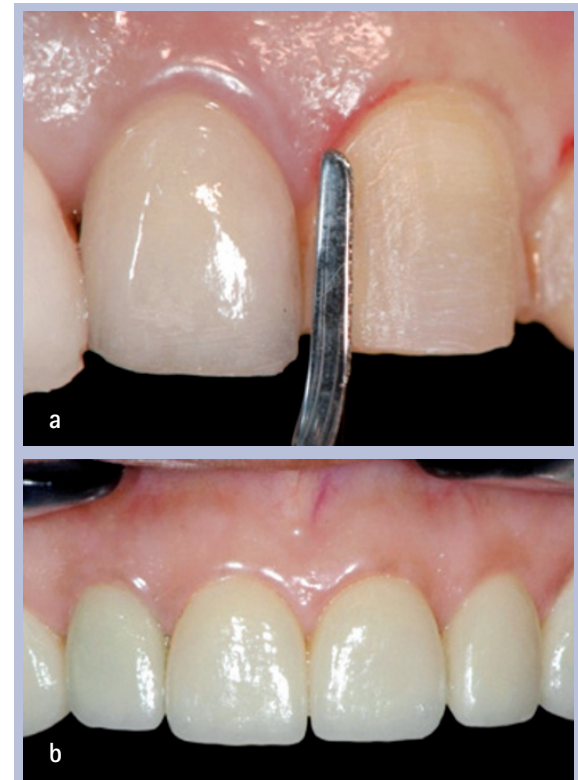

Fig. 10 Contribution of sono-abrasion in the preparation of veneers. a) Hemi-ogive shaped EMS $^{\circledR}$ DS-064A tip in action at the mesiolabial transition area of tooth $21 ; b)$ Clinical outcome, an example of the aesthetic and periodontal success of ceramic veneers

cavity. The elimination of such excesses and anatomical modification of the approximal surfaces of composite restorations can be achieved with stripping or shaping tips, as mentioned above, and this in both the anterior and posterior sectors (Figs 11a-c). 

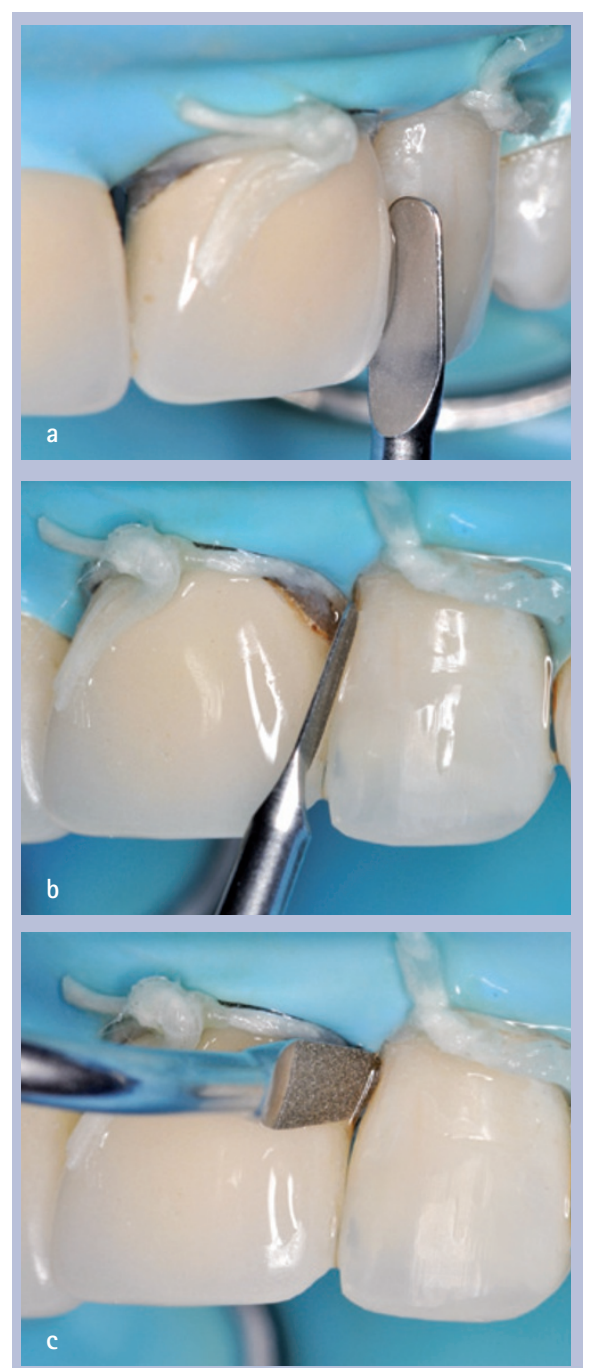

Fig. 11 Anatomical re-contouring and approximal finishing by abrasion of composite restorations with the SFM2 $\mathrm{F}^{\circledR}$ tip (SonicLine Stripping/Shaping ${ }^{\circledR}$, Komet): use the tip at the lowest power with water spray for finely controlled shaping

\section{DISCUSSION}

The concept of minimum intervention dentistry in oral medicine is primarily based on advanced biological science applied to the dental organ. Until recently, many cultural, economic and technical barriers thwarted the implementation of ultra-conservative and micro-invasive methods by the general practitioner. Emerging technologies do not remove all obstacles but contribute significantly to the evolution of dentistry in this direction and facilitate the integration of less invasive operative techniques in daily practice.

Thus, sono-abrasion techniques have displayed recognised good performance and have applications in all aspects of restorative dentistry. They should become part of the armamentarium of every practitioner interested in preserving dental tissue. ${ }^{21}$ Their use implies, as a general rule, the use of optical aids.

\section{Table 2 Basic range of ten sono-abrasive tips, proposed by the authors}

\begin{tabular}{l|l}
\hline Type of tip & Use \\
\hline $\begin{array}{l}1 \text { entirely abrasive tip: } \\
\text { pointed cone shape }\end{array}$ & $\begin{array}{l}\text { Prevention (sealant) } \\
\text { Opening and preparation of fissures }\end{array}$ \\
\hline $\begin{array}{l}1 \text { entirely abrasive tip: } \\
\text { round with collar shape }\end{array}$ & $\begin{array}{l}\text { Occlusal mini-cavities, } \\
\text { Access to dentinal lesions }\end{array}$ \\
\hline 2 MD 2-surface tips: & $\begin{array}{l}\text { Preparation of approximal mini-cavities } \\
\text { Finishing cavity margins } \\
\text { half round or hemispherical shape }\end{array}$ \\
\hline 2 MD 2-surface tips: & $\begin{array}{l}\text { Preparation of approximal boxes } \\
\text { approximal box shape }\end{array}$ \\
\hline 2 MD 2-surface tips: & $\begin{array}{l}\text { Interproximal clearing } \\
\text { Preparation of approximal margins } \\
\text { Preparation of veneers }\end{array}$ \\
\hline hemi-ogivale shape & $\begin{array}{l}\text { Access and interproximal clearing } \\
\text { Stripping and shaping } \\
\text { Trimming and finishing restorations }\end{array}$ \\
\hline 2 MD 2-surface tips: & lance shaped blade
\end{tabular}

As has been pointed out in this article, sono-abrasive techniques are not only for use in ultra-conservative cavity preparation, even if their primary use is as an alternative, less mutilating and safer method compared with rotating instruments. The technique is complementary to drilling, equally useful in the treatment of more advanced stages of tissue destruction. Favouring tissue conservation, it helps to perfect the treatment of major loss of substance while optimising the chances of pulp recovery and marginal adaptation of restorations. Finally, sono-abrasion is also beneficial for cosmetic dentistry; it allows the removal of enamel defects and facilitates preparations for prosthetic devices and partial or total veneers. To meet these various indications, a basic selection of versatile sonoabrasive diamond tips is proposed by the authors (Table 2).

In comparison with sound technology, ultrasound technology develops a better abrasive efficacy effective than mechanical. On the other hand, ultrasound technology presents a higher risk of producing enamel micro-cracks. Therefore, at the stage of finishing cavity margins, effective power should be reduced. More recent sonoabrasive systems (ultrasonic hand pieces and ultrasound generators) allow power levels to be adjusted so the tips can be used optimally and safely.

Hugo et al. showed in vitro that the hemispherical diamond tips of the Sonicsys system ${ }^{\circledR}$ (Kavo) allowed a high proportion of 'perfect joints' in composite restoration for approximal micro-cavities. ${ }^{17}$ Although since this initial study others have not confirmed these results, clinically it can be seen that bevelling and finishing cavity margins by sono-abrasion in general optimises the marginal adaptation of composite resin adhesive restorations and ceramic prosthetic items. We get regular edges with a homogeneous surface and clear margins, something much more difficult to achieve accurately with the rotary instruments. It therefore seems reasonable to consider that the sono-abrasion technique favours the stability of the tooth-restoration junction, provided that the subsequent restoration procedures are adequate.

Another topic of discussion concerns the quality of adhesion provided by these techniques after preparing cavities using sono-abrasion. The preparation technique induces various surface conditions and can affect adhesive performance. ${ }^{22}$ Preparation by sono-abrasion leaves a more homogeneous surface than preparation by air abrasion and various in vitro observations show surfaces partially devoid of smear layer and retaining only the dentinal plugs at the openings tubuli, ${ }^{7,23}$ but the formation of smear layer seems inevitable in vivo. According to Van Meerbeek et al. the adhesive performance of sono-abraded surfaces is equivalent to that obtained after using conventional diamond burs. ${ }^{24}$ In 2007, Tavares de Oliveira et al. showed that dentine surfaces treated by sono-abrasion provided efficacious retention, whatever the nature of the adhesive system, self-etch or etch-and rinsetypes. ${ }^{25}$ The practitioner will generally retain just one adhesive surface treatment, the type of enamel-dentinal adhesive being selected according to the clinical requirements, regardless of the choice of sono-abrasive preparation technique.

\section{CONCLUSION}

The evolution of surgical treatment in dentistry is a result of permanent interactions between scientific and technological advances. The sono-abrasion system 
is a perfect example of these links that have been part of minimum intervention dentistry for 20 years. It is a technique for the selective preparation of enamel and dentinal tissues with excellent relationships between efficacy, quality and safety. It is accessible and easily applied by any practitioner seeking to develop restorative treatments that respect the principle of economy of tissue. It has many indications, which cover the whole field of preventive, conservative and restorative oral medicine. For the authors, this technology is both alternative and complementary to rotary instrumentation, essential for preserving tissue and for achieving crisp and clean preparation margins and compatible with direct and indirect adhesive restoration techniques.

The small number of clinical trials of a high standard of evidence on the assessment of sono-abrasive preparations should encourage compliance with the technical rules and clinical procedures, and encourage the monitoring of the scientific literature.

The authors would like to thank Claudie DamourTerrasson, publishing director of the Groupe Information Dentaire, Paris, France, for the authorisation of translation and publication of the series in the BDJ; and Dr Avijit Banerjee for his support.

1. Lasfargues J J. Evolution des concepts en odontologie conservatrice. Du modèle chirurgical invasif au modèle médical préventif. Info Dent 1998;
40: $3111-3124$.

2. Colon P. Regards sur les évolutions de l'odontologie conservatrice sur ces 20 dernières années. Réalités Cliniques 2010; 21 : 25-32.

3. Lasfargues J J, Colon P. Odontologie conservatrice et restauratrice. Tome 1: une approche médicale globale. France: Ed CdP, Wolters Kluwer, 2010.

4. Banerjee A, Watson T F, Kidd E A. Dentine caries excavation: a review of current clinical techniques. BrDent J 2000; 188: 476-482.

5. Ricketts D N . Pitts N B. Novel operative treatment options. Monogr Oral Sci 2009; 21: 174-187.

6. Hugo B, Stassinakis A. Preparation and restoration of small interproximal carious lesions with sonic instruments. Pract Periodont Aesthet Dent 1998; 10: 353-359.

7. Colon P, Lasfargues J J. Apport de la sono-abrasion en microdentisterie adhésive. Réalités Cliniques 1999: 10: 251-270.

8. Koubi S, Tassery H. Sonic and ultrasonic devices in ultraconservative classe 2 restorations. Minimally invasive dentistry J Cont Dent Pract 2008; 9: 155-165.

9. Borges C F, Magne P, Pfender E, Heberlein J. Dental diamond burs made a new technology. J Prosthet Dent 1999; 82: 73-79.

10. Trava-Airoldi V J, Corat E J. Very adherent CVD diamond film on modified molybdenum surface. Diamond Relat Mater 2002; 11: 532-535.

11. Vieira A S, dos Santos M P, Antunes L A, Primo L G, Maia $L C$. Preparation time and sealing effect of cavities prepared by an ultrasonic device and a high-speed diamond rotary cutting system. J Oral Sci 2007; 49: 207-211.

12. Opdam N J, Roeters J J, van Berghem E, Eijsvogels $E_{\text {, }}$ Bronkhorst E. Microleakage and damage to adjacent teeth when finishing Class II adhesive preparations using either a sonic device or bur. Am J Dent 2002; 15: 317-320.

13. Yazici A R, Ozgunaltay G, Dayangac B. A scanning electron microscopic study of different caries removal techniques on human dentin. Oper Dent 2002; 27: 360-366.

14. Cardoso M V, Coutinho E, Ermis R B et al. Influence of dentin cavity surface finishing on micro-tensile bond strength of adhesives. Dent Mater 2008; 24: 492-501.

15. Weisrock G, Terrer E, Couderc G et al. Naturally aesthetic restorations and minimally invasive dentistry. J Minim Interv Dent 2011; 4: 1-12.

16. Neves A, Coutinho E, De Munck J, Van Meerbeek B. Caries-removal effectiveness and minimalinvasiveness potential of caries-excavation techniques: a micro-CT investigation. J Dent 2011; 39: 154-162.

17. Hugo B, Stassinakis A, Hofmann N, Schmitz B, Klaiber B. In vitro study of marginal quality of small approximal composite fillings. Schweiz Monatsschr Zahnmed 2001; 111: 19-27.

18. Lasfargues J J, Louis J J, Kaleka R. Classification des lésions carieuses. De Black au concept actuel par sites et stades. EMC Odontologie 2006; 23-069-A-10.

19. Decup F, Tison B, Lasfargues J J. Intervention restauratrice minimale : minicavités et miniobturations. EMC Odontologie 2006; 23-144-A-10.

20. Tison B, Decup F. Regard critique sur les cavités tunnel. Clinic 2011; 32: 543-550.

21. Couderc G, Weisrock G, Terrer E et al. La sono abrasion en odontologie restauratrice. Info Dent 2012; 31: 23-26.

22. Cardoso M V, Coutinho E, Ermis R B et al. Influence of dentin cavity surface finishing on micro-tensile bond strength of adhesives. Dent Mater 2008; 24: 492-501.

23. Lasfargues J J, Colon P. Organization et instrumentation. In Odontologie conservatrice et restauratrice. Tome 1: une approche médicale globale. pp 415-448. France: Ed CdP, Wolters Kluwer, 2010.

24. Van Meerbeek B, De Munck J, Mattar D, Van Landuyt $\mathrm{K}$, Lambrechts P. Microtensile bond strengths of an etch $\&$ rinse and self-etch adhesive to enamel and dentin as a function of surface treatment. Oper Dent 2003: 28: 647-660.

25. Tavares de Oliveira M, Moreira de Freitas $P$, de Paula Eduardo C, Bovi Ambrosano G M, Giannini M. Influence of diamond sono-abrasion, air-abrasion and er: YAG laser irradiation on bonding of different adhesive systems to dentin. Eur J Dent 2007; 1: 158-166. 